\title{
EL MEJORAMIENTO INTEGRAL EN EL CAMPO DE LOS TRATAMIENTOS URBANÍSTICOS DE BARRIOS CON PROBLEMÁTICAS DE CRECIMIENTO INFORMAL Y RIESGOS AMBIENTALES. CASO: SECTOR ARROYO EL SALAO II, BARRANQUILLA-COLOMBIA'
}

\author{
Artículo de investigación - Recibido: 2 de Enero de 2016 - Aceptado: 25 de Marzo de 2016
}

\section{Leonardo Navarro²}

Universidad del Atlántico. Barranquilla, Colombia. leonardo_navarro@arquitecto.com

Para citar este artículo / to reference this article:

Navarro, L. (2016). El mejoramiento integral en el campo de los tratamientos urbanísticos de barrios con problemáticas de crecimiento informal y riesgos ambientales. Caso: Sector arroyo El Salao II, Barranquilla-Colombia. Módulo Arquitectura CUC, Vol.17 N¹, 115-132.

\begin{abstract}
Resumen
En este artículo de investigación se plantea una revisión crítica hacia los métodos y modelos metodológicos para desarrollar Proyectos de Mejoramiento Integral de Barrios Informales MIB como una de las herramientas de planificación y gestión de desarrollo territorial en Colombia que ha tenido gran impacto y utilidad con las acciones y tratamientos urbanísticas propuestas en distintos proyectos vigentes en el país. La pregunta que dio paso al proceso de la investigación fue ¿Es factible estructurar una visión de Mejoramiento Integral para el sector del Salao II en Barranquilla, teniendo en cuenta la problemática urbano-espacial que caracteriza al territorio y a la población presente del lugar?. Dicha formulación permitió la generación de una propuesta de diseño urbano que estructuró la información de campo y de la población que hizo parte del estudio.
\end{abstract}

Palabras clave

Tratamientos urbanísticos, geotecnia, riegos, inundaciones, mitigación, mejoramiento integral.

1 Artículo producto de la investigación para optar por el título de Magíster en Urbanismo y desarrollo territorial de la Universidad del Norte, Colombia.

2 Arquitecto graduado de la Universidad del Atlántico, especialista en Gerencia de obra del SENA. Actualmente se desempeña gerente de la empresa de construcción e investigación Metro Cubico 
THE OVERALL IMPROVEMENT IN THE FIELD OF URBAN

NEIGHBORHOODS WITH PROBLEMATIC TREATMENTS

INFORMAL GROWTH AND ENVIRONMENTAL RISKS.

CASE: BROOK SECTOR EL SALAO II, BARRANQUILLA, COLOMBIA.

\section{Abstract}

This article critically review research into methods and methodological models arises to develop projects Upgrading Informal Settlements Informal MIB as one of the tools for planning and management of territorial development in Colombia that has had great impact and utility stocks and planning treatments proposed in various projects existing in the country. The question which led to the investigation process was: Is it possible to structure a comprehensive vision for the sector Improvement Salao II in Barranquilla, considering the urban space problem that characterizes the territory and population of this place? This formulation allowed the generation of an urban design proposal that structured information field and the population was part of the study.

\section{Keywords}

Urban treatments, Geotechnical, Irrigation, Flood mitigation, Overall improvement. 


\section{Introducción}

En gran parte de América Latina y el Caribe, las soluciones de viviendas formales no produce el resultado esperado desde el punto de vista d costo y efectividad y no cubre las necesidades de la población en general, ni siquiera los lotes son asequibles para la población de bajos recursos debido al alto costo del suelo. Esto trae como consecuencia que el sector de población de muy bajos recursos busque la informalidad mediante invasiones o compras ilegales, llegando al hacinamiento u ocupación indebida sin ningún tipo de planeación generando baja calidad de vida, malas condiciones ambientales y muy pobre prestación de servicios públicos. Estos asentamientos informales no están enmarcadas ni pensadas dentro de las normas urbanísticas y dan solución de vivienda a un 20 y hasta en ciertos casos un 50 por ciento de la población de las ciudades más grandes de América Latina. (De los Ríos, 2006) Los barrios informales en la actualidad desde el punto de vista ambiental y del espacio público no han sido creados ni pensados de la manera como deberían serlo teniendo en cuenta su desarrollo formal. De igual manera no son desarrollados teniendo en cuenta el confort ni un análisis del mismo y tampoco la problemática de la comunidad. (García, 2014)
En el siglo XX, como resultado de procesos de transformación social, política, económica y cultural, la sociedad colombiana se convirtió en una sociedad urbana en su mayoría obviando los fuertes lazos rurales que había construido la política, violencia, la cultura y la economía. (Torres, Rincón y Vargas, 2009)

Los barrios informales eran llamados tugurios y la orden de las instituciones de gobierno en los años 50 era la erradicación de los mismos pero debido a su gran número y magnitud en área esa orden cambia y en los años 60 se puede decir que en Colombia la planeación a escala local empezó antes que a nivel nacional. Lo que se prueba claramente cuando el 5 de abril de 1951 se coloca en vigencia el plan piloto de Bogotá como norma urbanística, diseñado por Le Corbusier. El cuál constaba de 4 planes como lo eran el plan regional, plan metropolitano, plan urbano y plan del centro cívico. En cada escala se dan las recomendaciones referidas a las funciones de la ciudad moderna (Habitar, trabajar, cultivar el cuerpo y el espíritu y circular), establecidas en la Carta de Atenas (Cortés y Arias, 1987; pp. 106-107). (Romero, 2016). 
En gran numero la ciudad colombiana se ve afectada por el crecimiento desorganizado trayendo consecuencias negativas sobre el Plan de Ordenamiento Territorial (POT), el cual es una herramienta que permite la organización y gestión del territorio y dinamiza la funcionalidad de la ciudad. No obstante y muy a pesar de estas herramientas de planificación, las ciudades siguen con problemas de asentamientos ilegales, los cuales se definen como una ocupación ilegal de un terreno baldío y utilizado para el uso de vivienda, caracterizado por la carencia de servicios de infraestructura básica, condiciones de vivienda inapropiadas que ponen en riesgo la seguridad y salud de sus ocupantes. (Romañas, Vidal y Rodriguez, 2013). En el caso puntual de Barranquilla, la cual gracias al rio Magdalena se ha convertido en capital estratégica para el país, generando beneficios económicos con el restablecimiento del transporte fluvial y aparte de esto puede traer zonas de esparcimiento y espacios libres en toda su ribera. (López, 2014), los asentamientos informales han venido creciendo sobre todo en el suroccidente de la ciudad donde el suelo es un suelo de muy mala calidad generando una de las viviendas la cual no cumple con las normas sismo resistentes ni con las certificaciones de los materiales adecuados y resulta un factor agravante al momento de presentarse emergencias por deslizamientos en el sector. Así mismo a causa de la contaminación por material sólido y el vertimiento de residuos líquidos en las fuentes hídricas, se presentan desbordamientos de arroyos, trayendo consigo emergencias por inundaciones y enfermedades. (Romañas, Vidal y Rodriguez, 2013)

La investigación y proyecto de mejoramiento integral para el arroyo el Salao II buscó garantizar su adecuado funcionamiento en el papel como receptor de aguas pluviales, y estudiar las condiciones y procesos de alcantarillado pluvial y sanitario que permitiesen mitigar las afectaciones ambientales y sanitarias generadas, entre otras causas, por el vertimiento directo de las aguas servidas locales a la cuenca del arroyo en estudio.

\section{Metodología}

La investigación tuvo como eje orientador en el componente de la metodología la estructura que a continuación se presenta en el gráfico: 


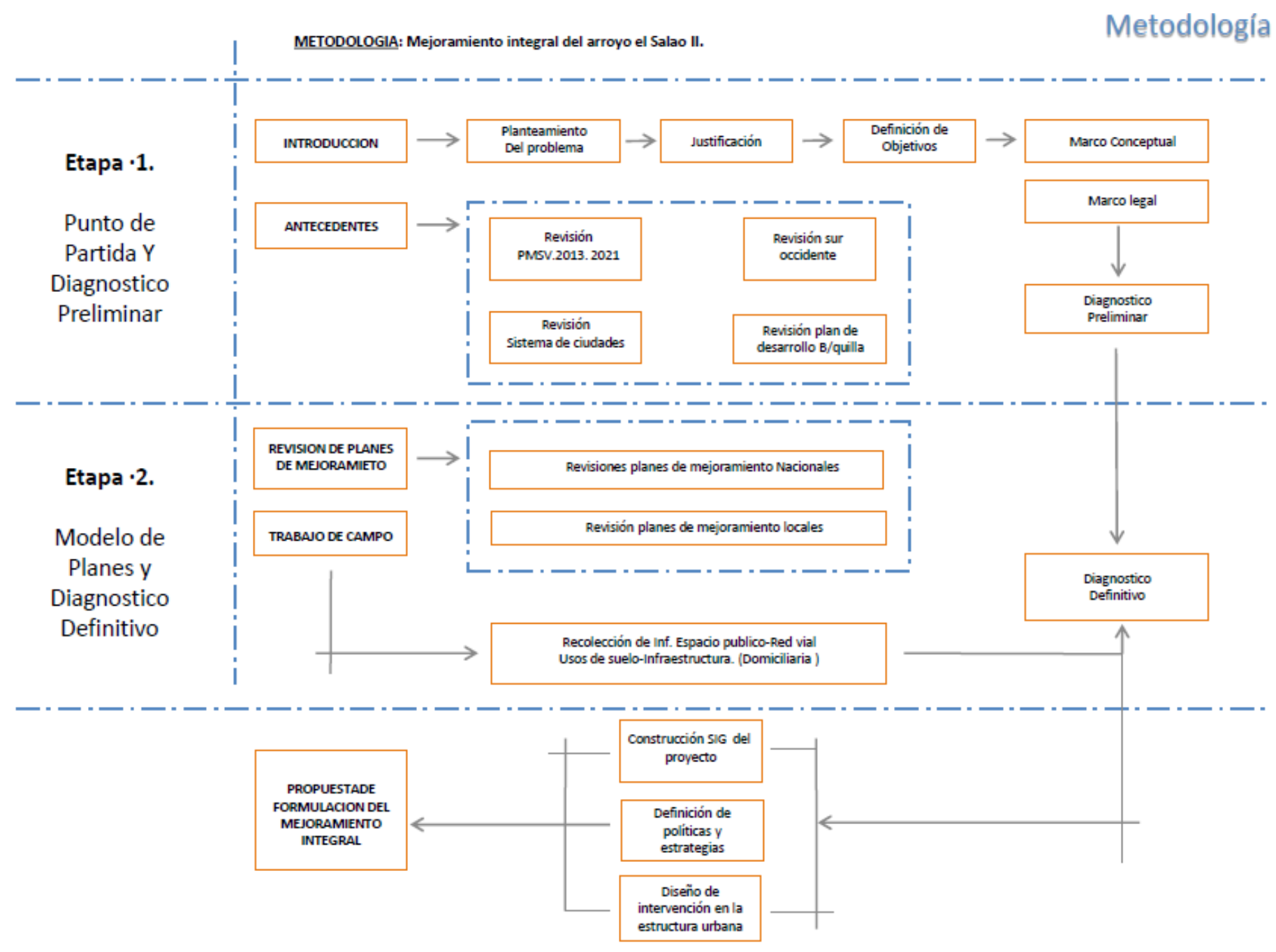

Gráfico 1. Proceso metodológico de la investigación MIB Salao II.

Fuente: El Mejoramiento Integral como método de desarrollo urbano en el tratamiento de la zona

El Salao II en la ciudad de Barranquilla, Colombia. 
El método utilizado en esta investigación fue el Análisis de cartografías, planos, imágenes satelitales y datos estadísticos poblaciones para la generación de conocimiento, lo cual permitió identificar el problema y establecer la relación entre sus partes con el todo. En este sentido, las variables estudiadas a fondo en el diagnóstico urbano del área permitieron inicialmente conocer las condiciones de la población en los ámbitos físicos y urbanos y su influencia en sus estilos $y$ formas de vida.

Las fuentes de información que permitirán caracterizar y conocer la problemática de estudio son: cartografía urbana del sector y ciudad, levantamientos fotográficos y planimétricos, censo de población del sector, etc. En lo referente a la toma de datos y recolección de información se llevó cabo en un solo momento; esto es, investigación de corte transaccional. Como técnicas de recolección de datos se utilizaron la Observación de Campo y la Encuesta; y ambas respectivamente se apoyaron en la utilización de Cuestionarios de preguntas y fichas de análisis de información de campo.

\section{Marco Conceptual}

Todos proyectos de mejoramiento integral de barrios deberían ponerse en práctica de manera ideal en un contexto de políticas urbanas y de desarrollo de vivienda que promuevan el correcto funcionamiento de los mercados inmobiliarios y generación de viviendas nuevas con facilidades para las personas con acceso de crédito solucionando así las necesidades de los lugares de menos ingresos (De los Ríos, 2006). De igual manera tener en cuenta el cuidado del ecosistema como elemento compositivo del contexto relacionado con la conducta poblacional, en otras palabras, según palabras de Bascompte y Solé (2005) los asentamientos ilegales debido al crecimiento autónomo o sin planeación generan fragmentación del hábitat y desequilibrios ambientales. Por eso es de gran importancia que el proyecto de mejoramiento integral urbano se fundamente en la aplicación de tratamientos de unidades de paisaje tomando datos del suelo y clima, cobertura terrestre y uso de tierra, asentamientos humanos y morfología del terreno todo enmarcado en escalas adecuadas (Forman, 1995) 
De esta manera se pueden tomar decisiones adecuadas y asertivas, cambiando la idea o forma de cómo analizar la ciudad, no como la naturaleza dentro de la ciudad sino como ecología urbana, como un ecosistema completo. No se debe utilizar la naturaleza como decoración exterior sino como parte integral del desarrollo urbano y a recuperación de los asentamientos humanos. (Steiner, 2009) En este momento concepto de desarrollo sostenible bien aplicado podría modificar el proceso de producción para reducir el impacto ambiental mejorando las condiciones de crecimiento económico (Gudynas, 2000) apostando al mejoramiento de técnicas y eficiencia energética y por consecuencia el mejoramiento de los asentamientos mal desarrollados.

El mejoramiento integral de un lugar, sector o barrio debe tener en cuenta que los individuos tienen su espacio personal, el cual es producto de vivencias, desplazamientos información oral, escrita y visual recibida, estímulos y factores culturales generando un mapa mental el cual condiciona su comportamiento y aceptación del espacio social en general (Herreros, 2008) De igual manera el concepto de vulnerabilidad social es de gran relevancia en el análisis y estudio de la inseguridad social, la cual, distintos aspectos sociales de manera simultánea (Morales, 2013) y también se debe tener en cuenta para lograr una buena solución urbana, teniendo en cuenta que un "asentamiento urbano es el resultado de una serie de decisiones particulares sucesivas relacionados entre sí consecutivamente, pero sin referencia común a un planteamiento general previo". (González, 2009) Por esto está claro que el entorno urbano y los recursos espaciales deben ser diseñados desde una visión integral, que se genere desde todo punto de vista (Vermetti, 1990)

Al hablar de planificación del espacio, los autores como (Odum, 1992) el cual plantea que se deben tener en cuenta aspectos del territorio y la clasificación de los suelos por áreas de protección, productivas, de compromiso, y artificiales. Todo esto en paralelo al concepto de ecología y urbanismo, es necesario integrar y considerar que, si se habla de fenómenos y procesos urbanos, y de ciudad como elemento sistémico, también debe hablarse de 
metabolismo a nivel urbano. Esto es, una perspectiva de la ecología urbana de corte sociológico, bien fundamentada por la Escuela de Chicago. En palabras de (Sybrand, 1995) cuando dice que la ciudad no puede escapar de sus condiciones económicas, sociales y culturales; y menos aún, escapar de sus propias reglas bióticas y abióticas.

En el contexto nacional colombiano, históricamente se ha utilizado un modelo de crecimiento urbano establecido por el desarrollo predio a predio de manera independiente y sin ningún tipo de marco referencial o normativo, más como un concepto espontaneo, lo que genera inconvenientes al momento de la aplicación de principios establecidos en la constitución como la función social y ecológica de la propiedad. Esto se debe a la poca participación de los distintos sectores sociales y a las pocas herramientas que se tienen (Torres, 2009), esto sucede a pesar que existen políticas para el correcto funcionamiento y aplicación de las estrategias de intervención urbana como los Planes de Ordenamiento Territorial (POT) en el cual se establecen lineamientos para estos asuntos. Una acción urbana integral abarca el mejoramiento de la infraestructura básica, redes de agua, saneamiento, espacio público servicios de electricidad y titulación predial. (Conpes, 2009) En cuanto a los tratamientos urbanísticos, éstos responden a la clasificación del suelo y al diagnóstico que previamente se ha realizado en el POT. En el sector en estudio existen diferentes tratamientos urbanísticos, el mayoritario que es el de Mejoramiento Integral, también hay área a la cual se le ha asignado el tratamiento de consolidación y una pequeña área con tratamiento de desarrollo. (Alcaldia de Barranquilla, 2014)

\section{Resultados}

A partir del desarrollo y análisis del diagnóstico urbano y cada uno de sus componentes, se planteó un modelo de operacionalización de los principales problemas encontrados, a fin de establecer las bases de la propuesta de diseño de intervención de mejoramiento integral del sector y dentro de la dinámica de desarrollo urbano.

El Arroyo El Salao fue el principal agente natural y de mayor relevancia e influencia en los fenómenos de riesgos en el sector de estudio. 


\section{Tabla 1}

Operacionalización del diagnóstico urbano.

\begin{tabular}{|c|c|c|c|}
\hline \multicolumn{4}{|c|}{ OPERACIONALIZACIÓN DEL DIAGNÓSTICO SECTOR EL SALAO II } \\
\hline $\begin{array}{l}\text { PROBLEMA } \\
\text { IDENTIFICADO }\end{array}$ & CAUSAS & CONSECUENCIAS & PROPUESTA \\
\hline $\begin{array}{l}\text { Existencia de zonas } \\
\text { y locaciones con } \\
\text { distintos niveles } \\
\text { de riesgos y } \\
\text { categorías posibles } \\
\text { de intervención que } \\
\text { se inscriben dos } \\
\text { ámbitos: reubicación y } \\
\text { mitigación. }\end{array}$ & $\begin{array}{l}\text { Condiciones naturales } \\
\text { del territorio. } \\
\text { Formas y tipos de } \\
\text { asentamientos. } \\
\text { Afectaciones de la } \\
\text { actividad humana hacia } \\
\text { el territorio. }\end{array}$ & $\begin{array}{l}\text { Zonas con } \\
\text { deslizamientos de tierra y } \\
\text { remociones en masa de } \\
\text { terrenos. } \\
\text { Viviendas en riesgo de } \\
\text { derrumbes, y problemas } \\
\text { de erosión. }\end{array}$ & $\begin{array}{l}\text { Programa integral } \\
\text { de tratamiento del } \\
\text { riesgo natural, con } \\
\text { énfasis en procesos } \\
\text { de mitigación y } \\
\text { reubicación de } \\
\text { zonas de viviendas. }\end{array}$ \\
\hline $\begin{array}{l}\text { Reglamentación y } \\
\text { acciones urbanísticas } \\
\text { poco definidas del } \\
\text { componente de la } \\
\text { Gestión de los riesgos } \\
\text { y el manejo ambiental } \\
\text { que se presentan en la } \\
\text { zona Salao II. }\end{array}$ & $\begin{array}{l}\text { Presencia del arroyo } \\
\text { de gran caudal sin } \\
\text { procesos evidentes } \\
\text { de mantenimiento de } \\
\text { canales y tratamiento } \\
\text { de cauces. }\end{array}$ & $\begin{array}{l}\text { Procesos de } \\
\text { desbordamientos a } \\
\text { causa de basuras y } \\
\text { desechos, localizados } \\
\text { indebidamente en } \\
\text { algunos puntos del } \\
\text { recorrido del arroyo. }\end{array}$ & $\begin{array}{l}\text { Elaboración de } \\
\text { una línea base } \\
\text { reglamentaria } \\
\text { del componente } \\
\text { Gestión de riesgos } \\
\text { para la zona en } \\
\text { estudio. }\end{array}$ \\
\hline $\begin{array}{l}\text { Calidad de vida } \\
\text { deteriorada y en } \\
\text { riesgo, con pocas } \\
\text { oportunidades de } \\
\text { construcción de } \\
\text { ciudad y un urbanismo } \\
\text { incluyente. }\end{array}$ & $\begin{array}{l}\text { Vías peatonales tipo } \\
\text { senderos y calles con o } \\
\text { sin recubrimientos, las } \\
\text { cuales, no presentan } \\
\text { carácter de estructura } \\
\text { vial formal y urbana. }\end{array}$ & $\begin{array}{l}\text { Percepción de una } \\
\text { imagen urbana de poca } \\
\text { calidad con condiciones } \\
\text { que no permiten la } \\
\text { legibilidad de la ciudad y } \\
\text { el entorno. }\end{array}$ & $\begin{array}{l}\text { Programa integral } \\
\text { de vivienda } \\
\text { y dimensión } \\
\text { espacial urbana } \\
\text { con criterios de un } \\
\text { diseño incluyente, } \\
\text { ambiental y } \\
\text { paisajístico. }\end{array}$ \\
\hline $\begin{array}{l}\text { Criticar las normativas } \\
\text { y acciones estatales } \\
\text { para el trabajo de MIB } \\
\text { en la ciudad. }\end{array}$ & $\begin{array}{l}\text { Políticas y normativas } \\
\text { poco definidas } \\
\text { en niveles de } \\
\text { operacionalización o } \\
\text { lineamientos para MIB } \\
\text { con casos específicos }\end{array}$ & $\begin{array}{l}\text { Desarrollo territorial sin } \\
\text { modelos de intervención } \\
\text { MIB }\end{array}$ & $\begin{array}{l}\text { Desarrollar modelo } \\
\text { MIB basado en las } \\
\text { condicionantes del } \\
\text { sector en estudio. }\end{array}$ \\
\hline
\end{tabular}

Fuente: El Mejoramiento Integral como método de desarrollo urbano en el tratamiento de la zona El Salao II en la ciudad de Barranquilla, Colombia. 


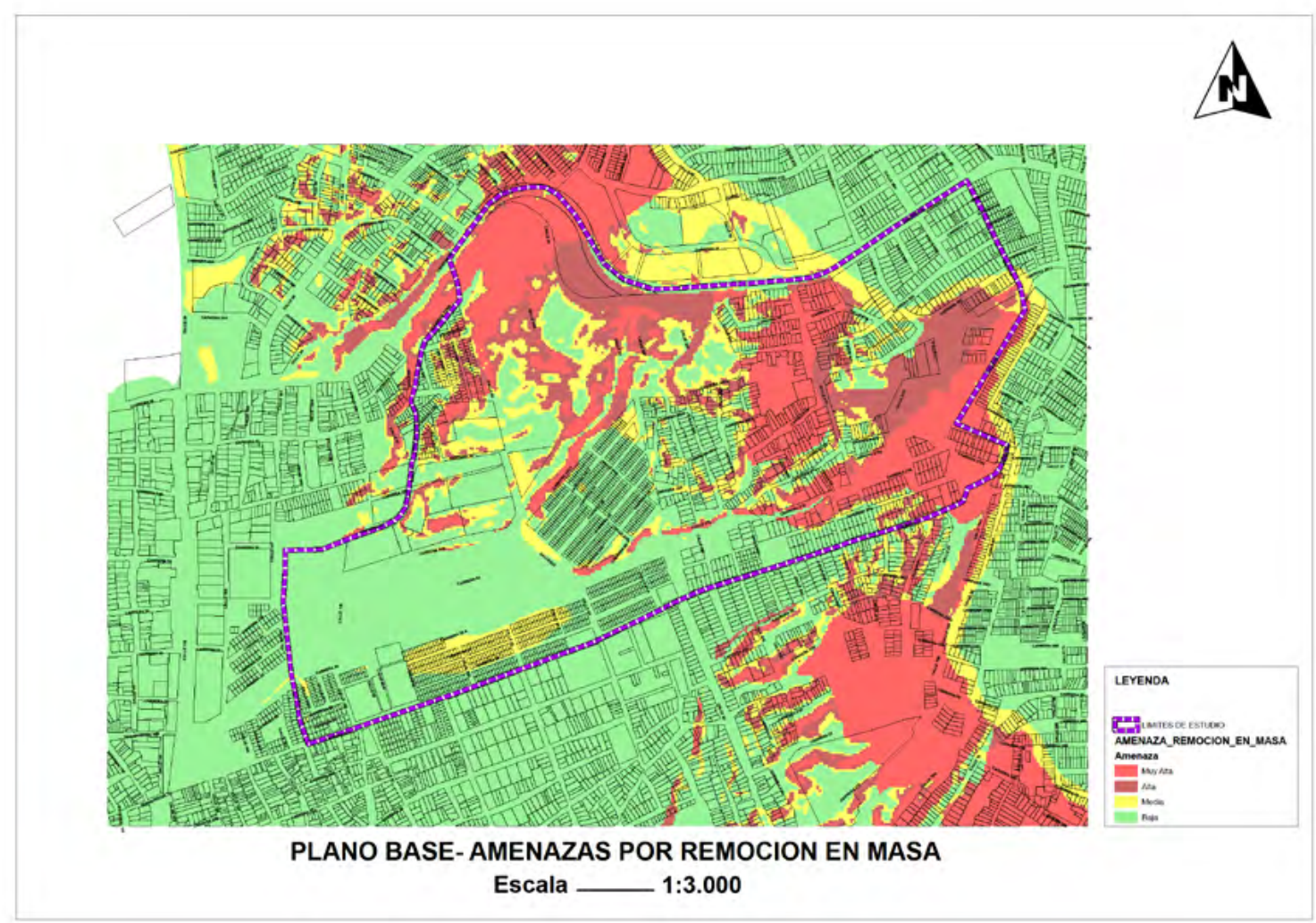

Gráfico 2. Plano base de remoción en masa. Sector Salao II.

Fuente: El Mejoramiento Integral como método de desarrollo urbano en el tratamiento de la zona El Salao II en la ciudad de Barranquilla, Colombia.

Muchas de las construcciones de los habitantes se desarrollaron muy cercanas a los bordes del arroyo, los cuales, pese a que presentaban parcialmente canalizaciones, se tornan perjudiciales por los desbordamientos a los que se somete la población en las temporadas de los niveles de riesgo de este asentamiento humano son los procesos de remoción en masa que ha sufrido el territorio, así como la erosión y el desgaste del suelo en el sector. El elemento hidrográfico del sector de estudio se ve definido por la presencia de drenajes para las escorrentías que en la ciudad se están comenzando a manejar e implementar. 


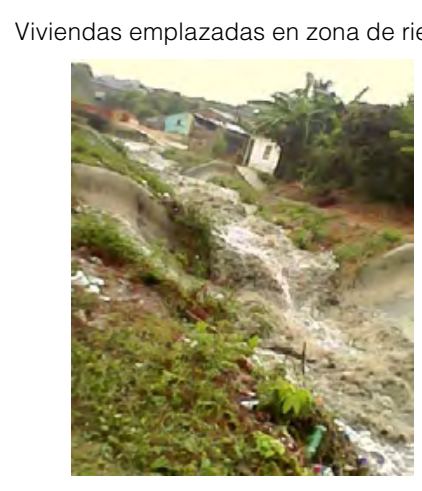

Tipos de senderos

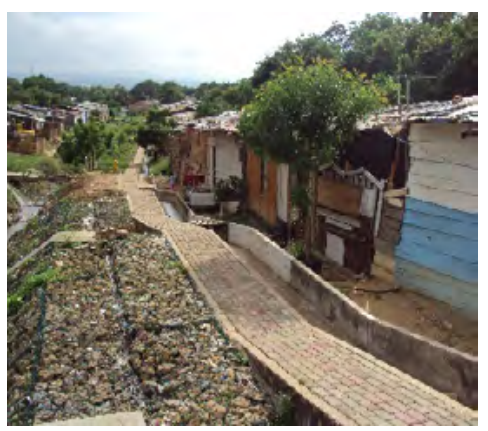

Canalizaciones del arroyo

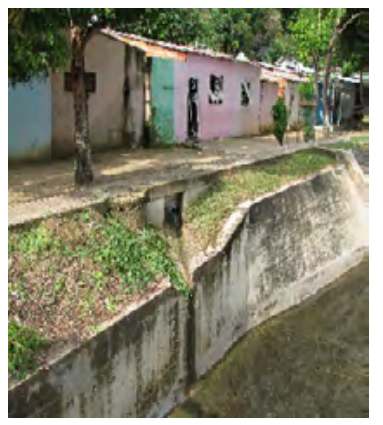

Entorno construido y materialidad

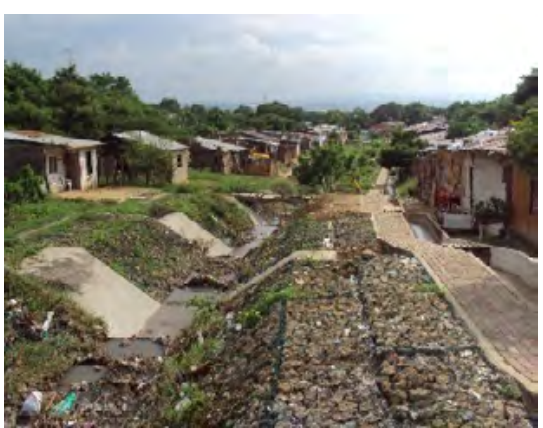

Gráfico 3. Agrupamiento de situaciones físicas del sector.

Fuente: El Mejoramiento Integral como método de desarrollo urbano en el tratamiento de la zona El Salao II en la ciudad de Barranquilla, Colombia.

El sector posee gran parte de territorio ocupado que debe ser reasentado por cuestiones ambientales y de riesgos. Algunas zonas son aptas para la edificabilidad bajo algunas consideraciones ambientales y constructivas, teniendo en cuenta las determinantes asociadas al arroyo y los procesos de remoción en masa, etc.

Las principales condiciones encontradas en el estudio fueron las siguientes:
- Muchas de las construcciones de los habitantes se desarrollan muy cercanas a los bordes del arroyo, los cuales, pese a que presentan parcialmente canalizaciones, se tornan perjudiciales por los desbordamientos a los que se somete la población en las temporadas de lluvias fuertes. 
- En los aspectos de tenencia de lotes y terrenos, la población del sector en su mayoría son poseedores o arrendatarios.

- Las principales vías vehiculares del sector son la carrera 38 y la Vía Circunvalar, las cuales se encontraron en regular estado a causa de deslizamientos de tierra y derrumbes. Los habitantes cuentan con calles para desplazarse desde el sector de estudio hacia los alrededores y otros sitios de la ciudad, utilizando los recorridos peatonales a lo largo del arroyo, y las desarrolladas sobre las calles y aceras restantes dentro del área de estudio.

- El espacio público del sector en estudio se definió a partir de vías pavimentadas y descubiertas, con la utilización de reducidas áreas de andén o circulaciones, interrumpidas en ocasiones por la disposición de los lotes y algunos determinantes físicos y ambientales como el arroyo o el terreno mismo.

- En un radio de acción con 500 mts con relación al sector de estudio se encontraron como equipamientos urbanos: Colegio Juan Manuel Olivella; un puesto de salud y una iglesia protestante Salón del reino. Con radio de acción de 1000 mts, están 5 colegios públicos, un
Hogar de Infancia y un Jardín infantil público. A $2000 \mathrm{mts}$ se encuentran: 22 colegios públicos, 4 Hogares de infancia y 4 Jardines infantiles públicos.

- La zona está constituida por los denominados arbustos, en forma de arbustal abierto. Manejan copas discontinuas y una distribución más o menos regular. A su vez, el paisaje del sector se compone por elementos arbustivos, es decir, aquellos que en conjunto forman un arbustal abierto. Del mismo modo, los herbazales abiertos caracterizan el paisaje natural del sector. En cuanto al grupo de los árboles, cabe decir que se localizan como instrumentos de sombras y en zonas circulables, tales como calles y senderos; mientras que éstos también aparecen localizados en lotes baldíos o terrenos semi-abiertos.

\section{Discusion}

Los resultados expuestos en este artículo, dejan al descubierto la magnitud de la problemática encontrada en los barrios del sur occidente de Barranquilla en materia ambiental. Teniendo en cuenta lo anterior, consideramos fundamental, como bien lo plantean Torres, Rincon y Vargas (2009) analizar el modelo de desarrollo urbano sobre 
cual se construye la ciudad, para poder entender, su desarrollo, ordenamiento espacial, así como el papel de la población, del Estado y la empresa privada, y hasta los conflictos de este proceso a través de la historia, tratando de entender el contexto y las políticas en las que se debe enmarcar el Programa de Mejoramiento Integral de Barrios. De igual forma, Torres, Rincón y Vargas (2009) señalan que es importante entender las apuestas sociales, políticas, económicas, culturales y ambientales que los gobiernos le imprimen a las políticas, planes, programas y proyectos expresados en los Planes de Desarrollo (2009).

En la ciudad de Barranquilla, la problemática en los barrios del sur occidente en cuanto a temas ambientales es muy amplia. Romañas, Vidal y Rodríguez (2013), señalan la presencia de factores de amenazas ambientales muy activos, tales como los arroyos y zonas de deslizamiento de terrenos, así como la baja calidad en la construcción de las viviendas que termina siendo un agravante para que se presenten emergencias por deslizamientos.

Con el anterior preámbulo, se puede analizar los resultados del estudio que se delimitó espacialmente en el sur-occidente de Barranquilla y en particular, el sector del Arroyo "El Salao II", el cual está ubicado entre la carrera 27 con la carrera 38 y con los puntos externos de la calle 80 y calle 83 con procesos naturales erosivos del terreno y suelos urbanos con características edafológicas que califican la zona dentro de un rango de alta susceptibilidad de erosión.

Se identificaron como principales problemas ambientales y espáciales, los siguientes:

- Niveles de deterioro del suelo y ocupaciones urbanísticas inadecuadas en el sector de estudio.

- Deterioro ambiental por causa de la contaminación y el mal manejo de las basuras y desechos orgánicos, produciendo estancamientos de suciedad y riesgos de salubridad.

- Los caudales que se manejan son demasiados altos para los canales existentes, produciendo desbordamientos de las aguas lluvias, ocasionando inundaciones y deterioro a las viviendas y las estructuras de éstas, localizadas a lo largo del borde del arroyo, propiciando a su vez el desarrollo de enfermedades de tipo infecciosas en la comunidad cercana. 


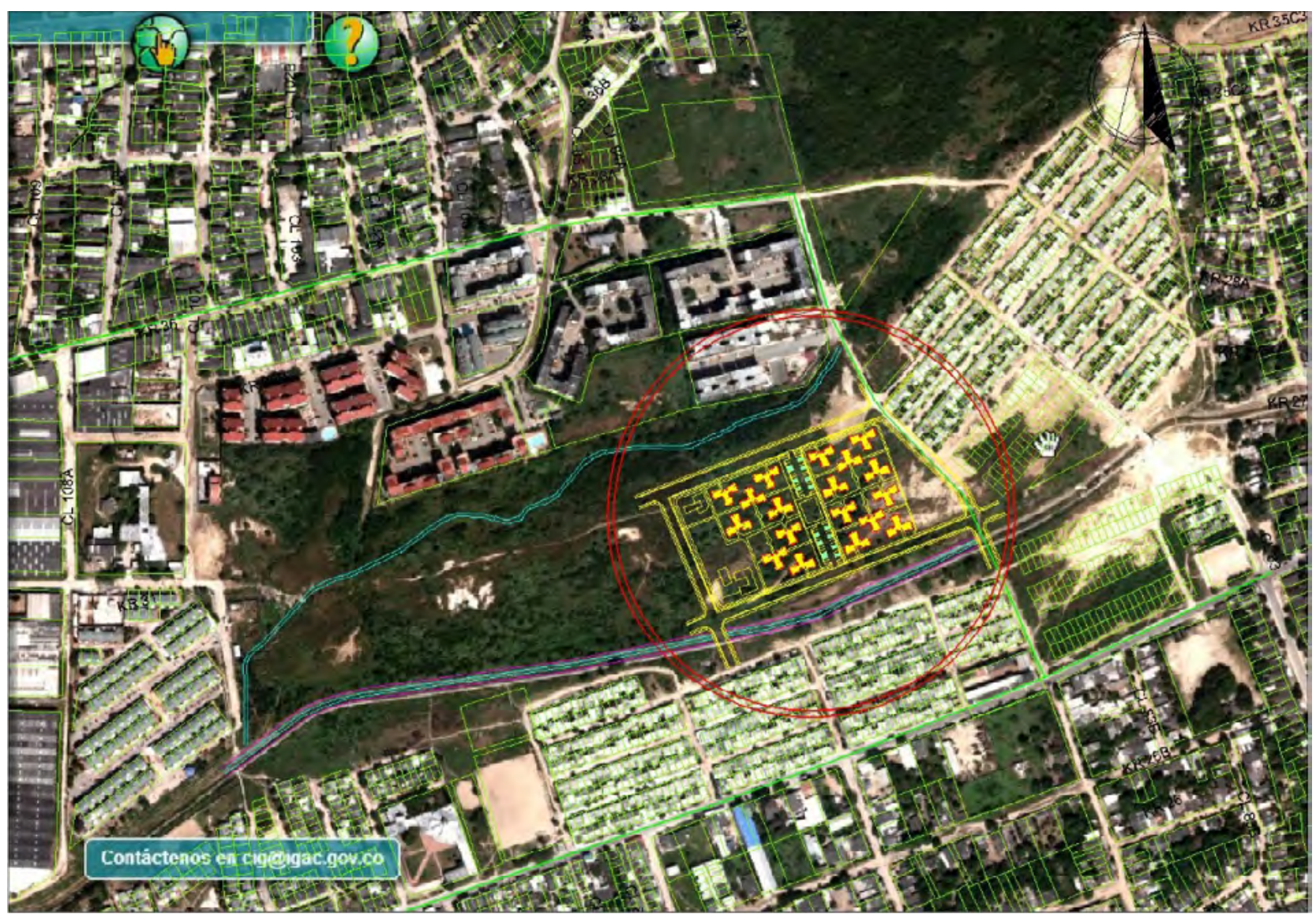

Gráfico 3. Imagen de Ubicación de la propuesta MIB salao II.

Fuente: El Mejoramiento Integral como método de desarrollo urbano en el tratamiento de la zona El Salao II en la ciudad de Barranquilla, Colombia.

Además, el sector de estudio presenta suelos de características antrópicas, dejando muy claro que, en alguna época, se realizaron allí trabajos de explotación de canteras para convertirse posteriormente en una zona de depósitos de escombros y basuras.
Se concluye finalmente que es necesario una propuesta de solución de vivienda de bajo costo y su localización respondió a las políticas de desarrollo urbano que prospectan una mejor calidad de vida y entorno urbano para aquellas poblaciones en estados de riesgo o en condiciones de vulne- 


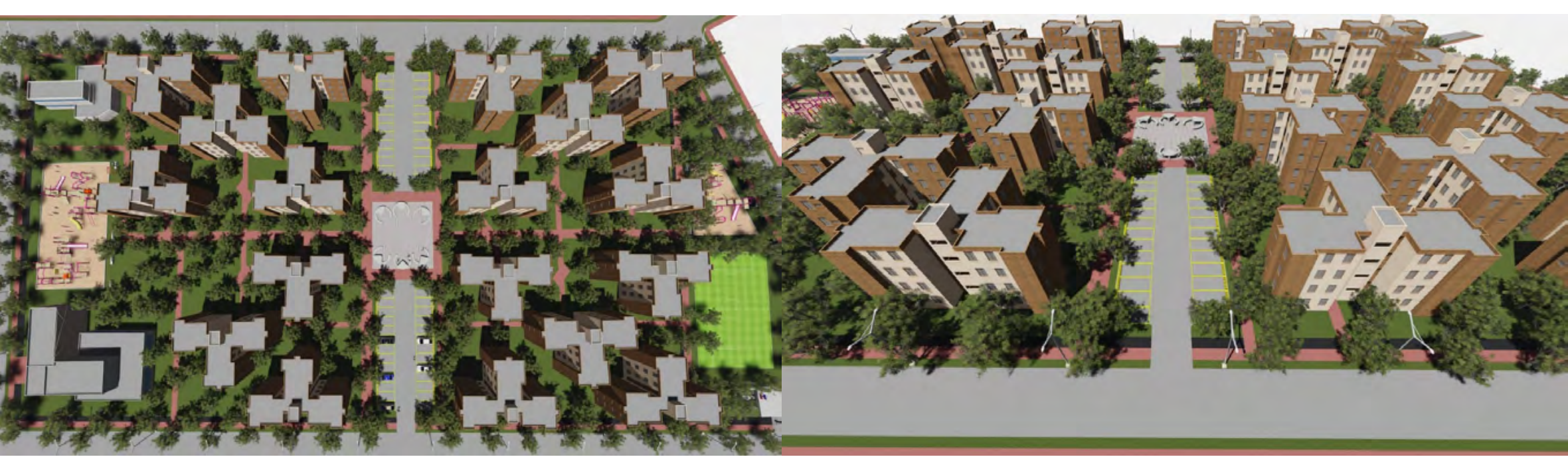

Gráfico 4. Imagen de bloques de vivienda MIB Salao II

Fuente: El Mejoramiento Integral como método de desarrollo urbano en el tratamiento de la zona El Salao II en la ciudad de Barranquilla, Colombia.
Gráfico 5. Imagen de la estética urbana y arquitectónica de los bloques de viviendas y el entorno.

Fuente: El Mejoramiento Integral como método de desarrollo urbano en e tratamiento de la zona El Salao II en la ciudad de Barranquilla, Colombia. rabilidad, asociadas por problemas del territorio y estilos de vida.

La ubicación del proyecto también respondió a las actividades de hábitat y pertenencia del sitio por parte de los pobladores del salao II, en la calle 84 con carrera 26B (borde del arroyo el Salao) ya que éstos han demostrado una arraigada identidad con el sector en cuanto a lugar de emplazamiento y significado como "lugar para vivir". Por este hecho, la propuesta retomó el concepto de "reubicación" para propender por el confort y el sentido de pertenencia del lugar, pero dentro de una nueva perspectiva de calidad en el espacio y de integración social; los cuales son aspectos marcados y de gran relevancia al diseñar proyectos MIB en Colombia.

El proyecto MIB Salao II tomó como referente la metodología y forma de planeamiento que presenta (Torres, 2009), caso Bogotá, de la siguiente manera: 


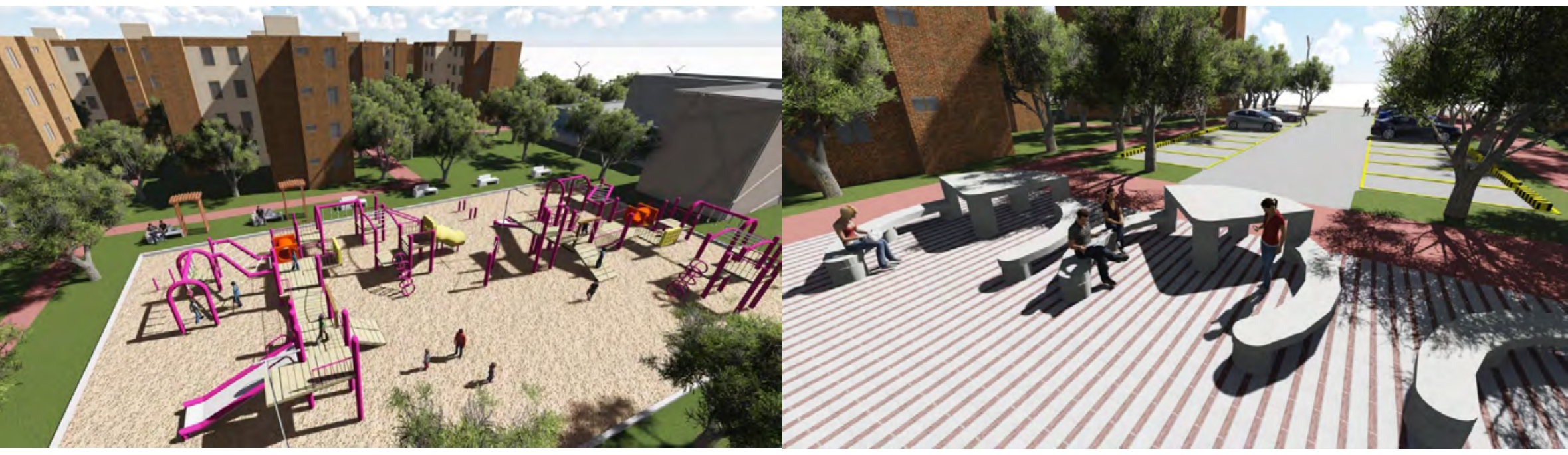

Gráfico 6. Imagen de propuesta de juego de niños y de esparcimiento social.

Fuente: El Mejoramiento Integral como método de desarrollo urbano en el tratamiento de la zona El Salao II en la ciudad de Barranquilla, Colombia.

Tabla 2

Operacionalización propuesta MIB Salao II.

\begin{tabular}{ccc}
\hline \multicolumn{2}{c}{ LÍNEAS DE ACCIÓN E INTERVENCIÓN DE LA PROPUESTA MIB SALAO II } \\
\hline $\begin{array}{c}\text { Organización y nuevos } \\
\text { desarrollos }\end{array}$ & Movilidad y servicios públicos & $\begin{array}{c}\text { Mitigación de riesgos y } \\
\text { vulnerabilidad sísmica }\end{array}$ \\
Reasentamientos & $\begin{array}{c}\text { Espacio público y formas de } \\
\text { desplazamiento }\end{array}$ & Diseño paisajístico \\
$\begin{array}{c}\text { Mejoramiento de vivienda } \\
\text { Cultura ciudadana y } \\
\text { convivencia }\end{array}$ & $\begin{array}{c}\text { Servicios públicos y nuevos usos } \\
\text { Sratamiento de bordes naturales }\end{array}$ & Áreas de protección y zonas verdes \\
\hline
\end{tabular}

Fuente: El Mejoramiento Integral como método de desarrollo urbano en el tratamiento de la zona El Salao II en la ciudad de Barranquilla, Colombia.

\section{Gráfico 7. Imagen de los mobiliarios, accesorios y} estética de los espacios sociales.

Fuente: El Mejoramiento Integral como método de desarrollo urbano en e tratamiento de la zona El Salao II en la ciudad de Barranquilla, Colombia. 


\section{Referencias}

Alcaldia de Barranquilla. (2014). Plan Estrategico de Barranquilla. Barranquilla: Alcaldia de Barranquilla.

Bascompte, J. y Solé, R. (2005). Margalef y el espacio o porque los ecosistemas no bailan sobre la punta e una aguja. Ecosistemas.

Conpes, C. (2009). Lineamientos para la consolidacion de la politica de mejoramiento integral de barrios MIB. Bogotá D.C.: Departamiento Nacional de Planeacion.

De los Ríos, S. (2006). Desarrollo de una base metodologica para fortalecer capacidades municipales en materia de identificacion, gestion y formulacion de proyectos de mejoramiento barrial. Santiago de Chile: CEPAL.

Forman, R. (1995). Land Mosaics: The ecology of Landscapes and regions. Cambrigde: Cambrigde University Press.

García, G. (2014). Recuperacion Ambiental Paisajistica El Rincón del Lago. Bogotá, D.C.: Universidad Catolica de Colombia.

González, G. (2009). De los Asentamientos Informales: Un asusnto de politica publica . Medellin: Universidad Nacional de Colombia.
Gudynas, E. (2000). Ecologia, economia y etica del desarrollo sostenible. La Paz: Academia Naional de la ciencias de Bolvia.

Herreros, J. (2008). La ciudad como espacio construido y vivido por la persona: implicaciones educativas. Contexto y Educacao, 45-67.

López, J. (2014). Eco Renovación Urbana del Borde de la Ciudad de Barranquilla que limita con el del Río Magdalena. Módulo Arquitectura CUC, 255-271.

Morales, S. (2013). Seguridad urbana y vulnerabilidad social en Ciudad Juarez. Un modelo desde la perspectiva de analisis espacial. Frontera Norte, 29-56.

Odum, E. (1992). Ecologia: bases cientificas para un nuevo paradigma. Barcelona: Vedra.

Romañas, J., Vidal, E. y Rodriguez, L. (2013). Una mirada al suroccidente de barranquilla: Módulo Arquitectura CUC, 115-127.

Romero, C. (2016). Evaluación del me joramiento integral de barrios: Valencia: Universidad Politecnica de Valencia. 
Steiner, F. (2009). Naturaleza y ciudad:cambios para el primer siglo urbano en los Estados Unidos. Ciudades, 13-31.

Sybrand, T. (1995). Ecopolis; strategies for ecologically sound urban development. Amsterdem: Backhuys Publishers.

Torres, C. (2009). Pobreza urbana y mejoramiento integral de barrios en Bogota. Bogotá, D.C.: Universidad Nacional de Colombia.
Torres, C., Rincon, J. y Vargas, J. (2009). Pobreza urbana y mejoramiento integral de barrios en Bogota. Habitat y vivienda. Bogota: Universidad Nacional de Colombia. Sede Bogotá.

Vermetti. (1990). Ecologia y ciudad: buscando modelos urbanos mas sostenibles. Salamanca. 